\title{
Prednisolone Sodium Metasulfobenzoate
}

National Cancer Institute

\section{Source}

National Cancer Institute. Prednisolone Sodium Metasulfobenzoate. NCI Thesaurus.

Code C1862.

A poorly adsorbed analog of prednisolone, a synthetic glucocorticoid with anti-

inflammatory and immunomodulating properties. After cell surface receptor attachment and cell entry, prednisolone enters the nucleus where it binds to and activates specific nuclear receptors, resulting in an altered gene expression and inhibition of proinflammatory cytokine production. This agent also decreases the number of circulating lymphocytes, induces cell differentiation, and stimulates apoptosis in sensitive tumor cells populations. ( $\mathrm{NCl})$ 